\title{
Occupational asthma from fungicides fluazinam and chlorothalonil
}

\author{
A Draper, P Cullinan, C Campbell, M Jones, A Newman Taylor
}

Occup Environ Med 2003;60:76-77

We report two cases of occupational asthma caused by sensitisation to powdered fungicides fluazinam and chlorothalonil, from the same fungicide formulation plant. Both developed work related lower respiratory symptoms after a latent interval of asymptomatic exposure. The diagnosis in each case was confirmed with a serial peak flow record in the workplace followed by specific inhalation tests. These fungicides are known to cause dermatitis; this report indicates that these compounds can induce specific immunological reactions in the airways as well as skin.

W e describe two cases of occupational asthma attributable to the fungicides fluazinam and chlorothalonil. Both are recognised causes of dermatitis, but only the latter has been previously reported to cause respiratory hypersensitivity.

\section{CASE 1-FLUAZINAM}

The patient is a 45 year old man. He is an ex-smoker with no previous history of respiratory or atopic disease, who had worked for 11 years in a fungicide formulation plant without suffering from respiratory or skin problems. The plant manufactures liquid fungicides from the suspension of insoluble powders in water. Production of these requires the handling of powdered ingredients that are "milled" to a small diameter (2 $\mu \mathrm{m})$ once in water. Three years before his referral a new fungicide formulation was introduced which contained the active ingredient fluazinam. Shortly after this he developed a sore throat while at work that continued throughout the subsequent 18 months. Production was moved to a different site and his symptoms improved; however, after reintroduction of the compound at the plant, six months before presentation, his sore throat recurred, now accompanied by work related wheeze and breathlessness. The medical history taken at this time records that his initial exposure to the compound was likely to have been high because the local exhaust ventilation had been shut off as a mistaken consequence of believing the product to pose an explosion risk. At the time of his referral his forced expiratory volume in one second $\left(\mathrm{FEV}_{1}\right)$ was $2.5 \mathrm{l}$ $(67 \% \text { predicted })^{1}$ before and $2.8 \mathrm{l}$ after inhalation of salbutamol; his histamine PC $20^{2}$ was $9.1 \mathrm{mg} / \mathrm{ml}$. Skin prick tests with common inhalant allergens did not provoke any immediate reactions.

Serial measurements of his peak flows performed over four weeks, recorded prior to referral, showed reduced values at work, lowest recording $160 \mathrm{l} / \mathrm{min}$ with an average of $334 \mathrm{l} / \mathrm{min}$. Diurnal variation on work days was $17-44 \%$ compared with $10 \%$ on rest days. Fluazinam is poorly soluble in water and alcohol and it was not possible to make assays of serum specific IgE antibodies to fluazinam conjugates. In order to test the diagnosis of fluazinam induced asthma he underwent specific inhalation tests using powdered fluazinam (>99\%

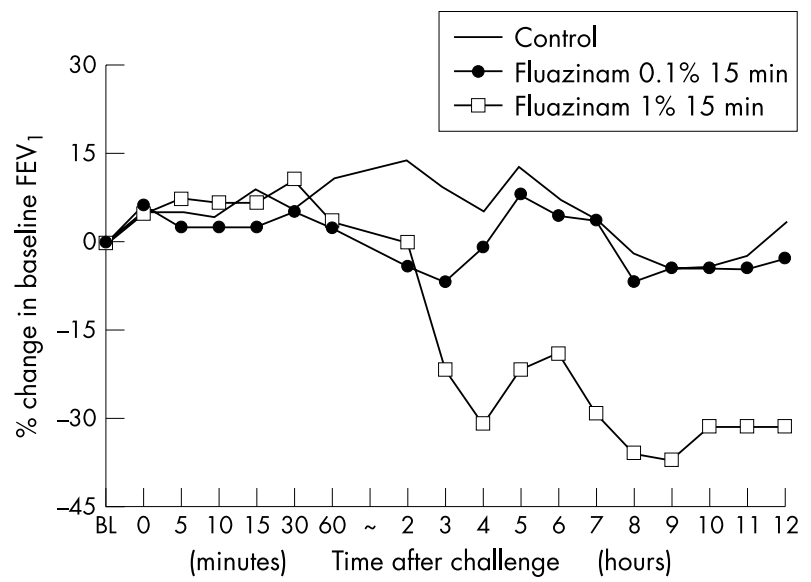

Figure 1 Fluazinam inhalation test. Baseline (BL) FEV, 2.55.

$\mathrm{w} / \mathrm{w})$ provided by Syngenta. Tests were undertaken on separate days, using a single blind, controlled dust tipping method. Exposure to an inert dust (lactose control) was followed by no significant change in his $\mathrm{FEV}_{1}$, over 12 hours, or at 24 hours. No reaction followed exposure to a mixture of 0.25 $\mathrm{g}$ fluazinam in $250 \mathrm{~g}$ lactose. Exposure, for 15 minutes, to a mixture of $2.5 \mathrm{~g}$ fluazinam in $250 \mathrm{~g}$ lactose was followed by a $35 \%$ fall in baseline $\mathrm{FEV}_{1}$ starting two hours after exposure with recovery by the following day (see fig 1). No other symptoms were reported by the patient. Twenty four hours after the test exposure, histamine PC20 had fallen ninefold to $1 \mathrm{mg} / \mathrm{ml}$. He was subsequently moved to a different part of the same factory, where he does not encounter fluazinam and has since remained asymptomatic.

\section{CASE 2-CHLOROTHALONIL}

The patient is a 53 year old man. He is a non-smoker with a history of seasonal rhinitis and atopy. He had worked for 13 years in the same fungicide plant as the first case. He gave a three year history of intermittent and occasional difficulty in breathing that he latterly related to work. He was moved to an office job in the same building but his symptoms persisted. He was prescribed inhaled corticosteroid and bronchodilator. Two months before his referral he was transferred to another plant on a trial basis. His symptoms improved and his need for bronchodilator inhalation reduced. The medical history taken at the time does not record any episode of high exposure, but the employee had worked with the compound for a 10 year period prior to developing symptoms.

On presentation his $\mathrm{FEV}_{1}$ was 3.11 ( $82 \%$ predicted $)^{1}$ with no improvement after inhaled salbutamol. He had immediate skin prick test responses to Dermatophagoides pteronyssinus and grass pollens, consistent with his history of seasonal rhinitis. His histamine PC20 was $>16 \mathrm{mg} / \mathrm{ml}^{2}$ Serial measurements of his peak flows performed over six weeks, recorded prior to 


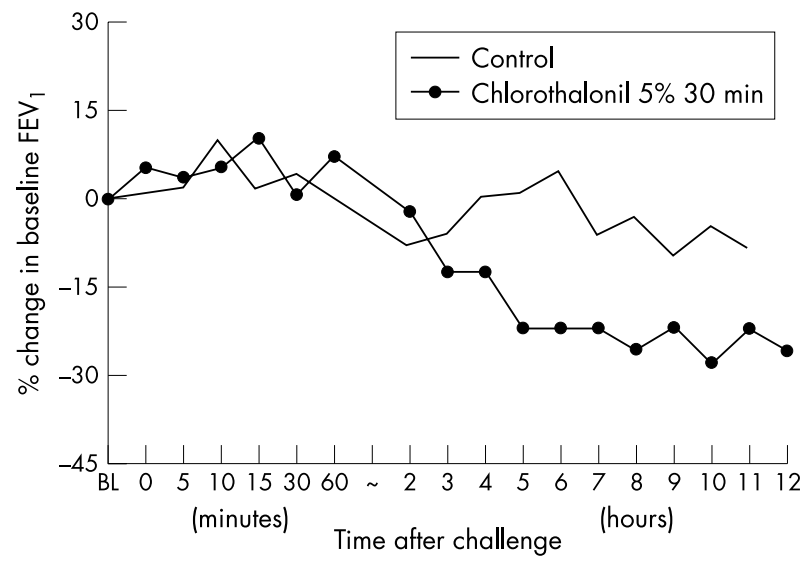

Figure 2 Chlorothalonil inhalation test. Baseline (BL) FEV 1 3.1.

referral, showed reduced values at work, lowest recording 190 $\mathrm{l} / \mathrm{min}$ with an average of $474 \mathrm{l} / \mathrm{min}$. Diurnal variation on work days was $15-40 \%$ compared with $4-10 \%$ on rest days. It was not possible to undertake assays for specific IgE as chlorothalonil was insoluble in water and alcohol. In order to identify the specific cause of his asthma the patient underwent specific inhalation tests using a single blind controlled dust tipping method with powdered chlorothalonil (>97\% w/w) and fluazinam $(>99 \% \mathrm{w} / \mathrm{w})$ provided by Syngenta. Exposures to lactose and increasing fluazinam/lactose mixtures (0.25-25 g in $250 \mathrm{~g}$ for up to 30 minutes) on separate days did not provoke a significant change in baseline $\mathrm{FEV}_{1}$ or histamine PC20. Exposure to a $12.5 \mathrm{~g}$ chlorothalonil in $250 \mathrm{~g}$ lactose mixture (for 30 minutes) provoked a fall in $\mathrm{FEV}_{1}$ of $20 \%$ beginning after three hours and lasting for a further nine hours(see fig 2). No other symptoms were reported in association with this fall in $\mathrm{FEV}_{1}$. Twenty four hours after this exposure the histamine PC20 fell from $>16 \mathrm{mg} / \mathrm{ml}$ to $9.0 \mathrm{mg} / \mathrm{ml}$. The patient's symptoms have resolved and not recurred since he was moved to another job in a different part of the factory.

\section{DISCUSSION}

The histories, work related pattern of serial peak flow measurements, and the responses to specific inhalation tests indicate that the asthma in these two men was the outcome of a hypersensitivity response to inhaled fungicides, both encountered at work. Fluazinam (CAS name 3-chloro-N-[3chloro-2,6-dinotro-4-(trifluromethyl)phenyl]-5-(trifluoromethyl)-2-pyridinamine) is a broad spectrum fungicide which was first marketed in 1992 and is now widely used in the protection of flower bulbs and root vegetables. Regulatory testing, in vitro and in an animal model, confirmed its potential as a skin sensitiser. The compound was examined in an experimental model for respiratory sensitisation (mouse IgE) which suggested that it did not have significant capacity to cause respiratory sensitisation. ${ }^{3}$ Shortly after its introduction a delayed type, contact dermatitis, attributed to fluazinam, was described in nine Dutch farmers. ${ }^{4}$ This report did not mention respiratory symptoms and to the best of our knowledge, case $l$ is the first report of asthma caused by fluazinam.
Chlorothalonil (CAS name 2,4,5,6 tetrachloro-1,3benzenedicarbonitrile) has been produced since the 1960s. It is a broad spectrum fungicide, used in horticulture, agriculture, and as a wood preservative. Regulatory tests showed it to have the potential to be a weak skin sensitiser. There are four reports of contact dermatitis $s^{5-8}$ and one report of contact urticaria and anaphylaxis ${ }^{9}$ attributable to chlorothalonil. The cases of dermatitis were confirmed by patch testing. There is one case report of asthma (confirmed by inhalation tests) attributed to a chlorothalonil suspension in commercial use. ${ }^{10}$ To our knowledge this is the first case report of occupational asthma specifically caused by chlorothalonil powder.

The clinical findings in these two cases are consistent with a hypersensitivity reaction: asthma has occurred in only a minority of those exposed and only developed after a period of symptom free exposure to the specific agents in concentrations that subsequently provoked a reaction; respiratory symptoms in both cases were work related and associated with work related falls in peak flow; inhalation tests with the specific agent provoked a late phase asthmatic response and increase in bronchial hyperresponsiveness. We were unable to measure specific IgE antibodies in serum. Our report, together with earlier reports of dermatological responses (both contact dermatitis and urticaria) and one of occupational asthma, indicate that these compounds can induce specific immunological reactions in the airways as well as skin.

\section{Authors' affiliations}

A Draper, P Cullinan, M Jones, A Newman Taylor, Department of Occupational \& Environmental Medicine, Royal Brompton Hospital \& NHLI, 16 Manresa Road, London SW3 6LR, UK

C Campbell, Syngenta International AG, WRO 1007.1.37, Werk Rosental, Schwarzwaldallee 215, CH-4025 Basel, Switzerland

Correspondence to: Dr A Draper, Chest Clinic, St George's Hospital, Blackshaw Road, Tooting, London SW17 OQT, UK; adrian@adraper.freeserve.co.uk

Accepted 14 May 2002

\section{REFERENCES}

1 Crapo RO, Morris AH, Gardner RM. Reference spirometric values using techniques and equipment that meet ATS recommendations. Am Rev Respir Dis 1981;123:659-64.

2 Cockcroft DW, Killian DN, Mellon JJ, et al. Bronchial reactivity to inhaled histamine: a method and clinical survey. Clin Allergy 1977;7:235-43.

3 Campbell C. Personal communication, 2001.

4 Sabapathy NN, van Ginkel CJW. Allergic contact dermatitis from the newly introduced fungicide fluazinam. Contact Dermatitis 1995;32:160-162.

5 Bach B, Pedersen NB. Contact dermatitis from a wood preservative containing tetrachloroisophthalonitrile. Contact Dermatitis 1980;6:142.

6 Bruynzeel DP, van Ketel WG. Contact dermatitis due to chlorothalonil in floriculture. Contact Dermatitis 1986;14:67-8.

7 Liden C. Facial dermatitis caused by chlorothalonil in a paint. Contact Dermatitis 1990;22:206-11

8 Penagos H, Jimenez V, Fallas V, et al. Chlorothalonil, a possible cause of erythema dyschromicum perstans (ashy dermatitis). Contact Dermatitis 1996;35:214-18.

9 Dannaker CJ, Maibach HI, O'Malley M. Contact urticaria and anaphylaxis to the fungicide chlorothalonil. Cutis 1993;52:312-15.

10 Honda I, Kohrogi $H$, Ando $M$, et al. Occupational asthma induced by the fungicide tetrachloroisophthalonitrile. Thorax 1992;47:760-1. 